Article

\title{
Synthesis of Poly(norbornene-methylamine), a Biomimetic of Chitosan, by Ring-Opening Metathesis Polymerization (ROMP)
}

\author{
$\mathrm{Na} \mathrm{Li}^{\dagger}{ }^{\dagger}$, Huanhuan Wang ${ }^{\dagger}$, Xiaosai $\mathrm{Qu}$ and $\mathrm{Yu}$ Chen * \\ School of Materials Science \& Engineering, Beijing Institute of Technology, Beijing 100081, China; \\ bitna_li@foxmail.com (N.L.); Wangh208@126.com (H.W.); shawnqu@foxmail.com (X.Q.) \\ * Correspondence: bityuchen@bit.edu.cn; Tel.: +86-010-68912370 \\ + These authors contributed equally to this work.
}

Received: 12 June 2017; Accepted: 9 July 2017; Published: 14 July 2017

\begin{abstract}
ROMP is an effective method for preparing functional polymers due to its having characteristics of "living" polymerization and rapid development of catalysts. In the present work, poly(norbornene-methylamine), a mimic of chitosan, was synthesized via ROMP reaction. The amino-protected product, 5-norbornene-2-( $N$-methyl)-phthalimide, was prepared by a reaction of 5-norbornene-2-methylamine with phthalic anhydride, which was then subjected to the ROMP reaction in the presence of Hoveyda-Grubbs 2nd catalyst to afford poly(norbornene( $N$-methyl)-phthalimide). The target product, poly(norbornene-methylamine), was obtained by deprotection reaction of poly(norbornene-( $N$-methyl)-phthalimide). The products in each step were characterized by FTIR and ${ }^{1} \mathrm{H}-\mathrm{NMR}$, and their thermal stabilities were determined by TG analysis. The effects of molar ratio between monomer ([M]/[I]) and catalyst on the average relative molecular weight $(\overline{M n})$ and molecular weight distribution of the produced polymer products were determined by gel permeation chromatography (GPC). It was found that the $\overline{M n}$ of poly(norbornene-( $N$-methyl)-phthalimide) was controllable and exhibited a narrow polydispersity index (PDI) ( 1.10). The synthesis condition of 5-norbornene-2-( $N$-methyl)-phthalimide was optimized by determining the yields at different reaction temperatures and reaction times. The highest yield was obtained at a reaction temperature of $130{ }^{\circ} \mathrm{C}$ and a reaction time of $20 \mathrm{~min}$. Our work provides a new strategy to synthesize polymers with controllable structures and free $-\mathrm{NH}_{2}$ groups via ROMP.
\end{abstract}

Keywords: ROMP; poly(norbornene-methylamine); controllable; living polymerization; chitosan

\section{Introduction}

ROMP has been an effective method for preparing functional polymers due to its having the characteristics of living polymerization [1,2] and rapid development of catalysts [3-6]. The mechanism of ROMP is substantially different from other polymerization reactions, such as radical polymerization and anionic polymerization. During an ROMP reaction, the double bond translocates continuously, the chain gradually grows, and the double bond of monomer molecules remains in the generated polymer molecules as shown in Scheme $1[7,8]$. The resultant polymer of ROMP can inherit the single bond, double bond and even the ring structure of a double-ring monomer. Therefore, ROMP can be used to prepare completely alternating copolymer [9,10]. In addition, its advantages of mild reaction conditions, high reaction rate, absence of chain transfer and termination reaction in most cases provide the polymers a narrow molecular weight distribution. Over the last few decades, many new controllable polymers, such as new homopolymers, telechelic copolymers [11-13], block copolymers [14-16], graft copolymers [17-19], liquid crystal polymers [20], and so on, have been synthesized by ROMP. These 
novel polymers have been extensively employed as conductive materials, porous network materials, self-healing materials and biomedical materials.

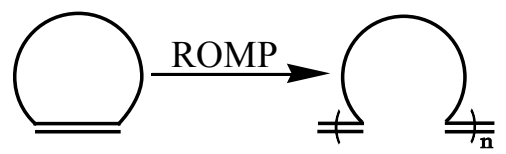

Scheme 1. The reaction mechanism of ROMP.

Norbornene (NBE) and its derivatives are highly reactive due to their special cyclic structure, and thus are prone to a variety of polymerization reactions, such as radical polymerization, anionic polymerization, vinyl addition polymerization [21], and ROMP, in the presence of catalysts. Wherein, ROMP is one of the most commonly used polymerization methods due to its special reaction mechanism and mild reaction conditions. The ROMP of boron-, fluorine-, chlorine-, nitrile-, silicon-, silicon-, oxygen-, amides- and acid anhydride- derivatives of NBE has been well studied [22-27]. However, the ROMP of amino NBE has rarely been reported. Similar to chitosan, the cyclic polymers bearing $-\mathrm{NH}_{2}$ usually possess excellent hydrophilicity, high reactivity and excellent complexing abilities with metal ions [28], and thus they can be applied in a variety of fields. In addition, the $-\mathrm{NH}_{2}$ can be converted to $-\mathrm{NH}_{3}{ }^{+}$in acidic conditions, which provides a $\mathrm{pH}$ sensitivity to the polymers. Therefore, these polymers are promising candidate materials for gene transfection vectors and drug release.

In the present work, poly(norbornene-( $N$-methyl)-phthalimide) was synthesized by the ROMP of 5-norbornene-2-( $\mathrm{N}$-methyl)-phthalimide, an amino-protected product of 5-norbornene-2-methylamine. Its anhydride group was then deprotected to afford poly(norbornene-methylamine). The synthesis route is shown in Scheme 2. Our work provides a new strategy for the synthesis of polymers bearing $-\mathrm{NH}_{2}$ groups with controllable structures by ROMP. The intermediate product, poly(norbornene( $N$-methyl)-phthalimide), can be used to prepare block copolymers with other unsaturated compounds. It also can be considered as a mimetic of natural chitosan with appropriate modifications. The produced polymer can be potentially applied in a variety of fields, such as gene transfection vectors, controlled-release carriers for functional drugs, and so on.

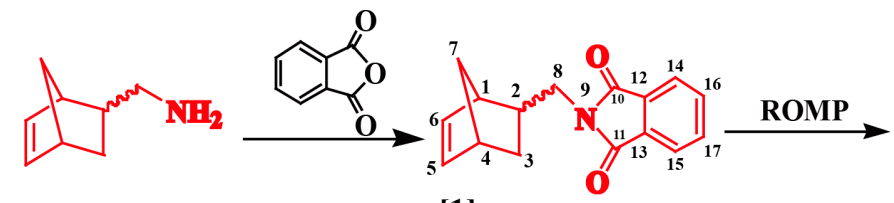

[1]

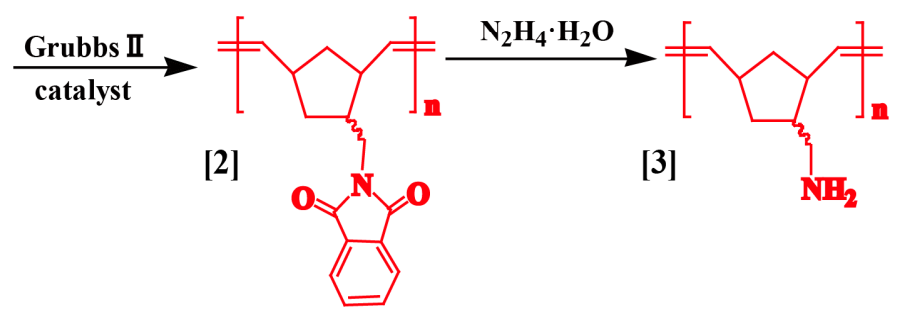

Scheme 2. The reaction route for preparing poly(norbornene-methylamine) by ROMP.

\section{Results and Discussion}

\subsection{FTIR Characterization}

A comparison between the FTIR spectra of phthalic anhydride and 5-norbornene-2-( $N$-methyl)phthalimide (product 1 ) indicates that the symmetric and asymmetric stretching vibration absorption peaks of $\mathrm{C}=\mathrm{O}$ groups shifted from $1762 \mathrm{~cm}^{-1}$ and $1855 \mathrm{~cm}^{-1}$ (phthalic anhydride) to $1709 \mathrm{~cm}^{-1}$ and 
$1768 \mathrm{~cm}^{-1}$ (5-norbornene-2-(N-ethyl)-phthalimide), respectively, due to the formation of a lactam group between the $-\mathrm{NH}_{2}$ group and $\mathrm{C}-\mathrm{O}-\mathrm{C}$ group (Figure 1). The N-H stretch vibration absorption peaks of the $-\mathrm{NH}_{2}$ in 5-norbornene-2-methylamine at $1573 \mathrm{~cm}^{-1}, 1483 \mathrm{~cm}^{-1}$ and $3330 \mathrm{~cm}^{-1}$ disappeared after the reaction with phthalic anhydride, indicating the formation of phthalimide group. The peak at $3000 \mathrm{~cm}^{-1}$ was attributed to the stretching vibration of $-\mathrm{CH}_{2}$ - groups of product 1 . The peaks at $2860 \mathrm{~cm}^{-1}$ and $3062 \mathrm{~cm}^{-1}$ were due to the stretching vibration of the unsaturated $=\mathrm{CH}$ group.

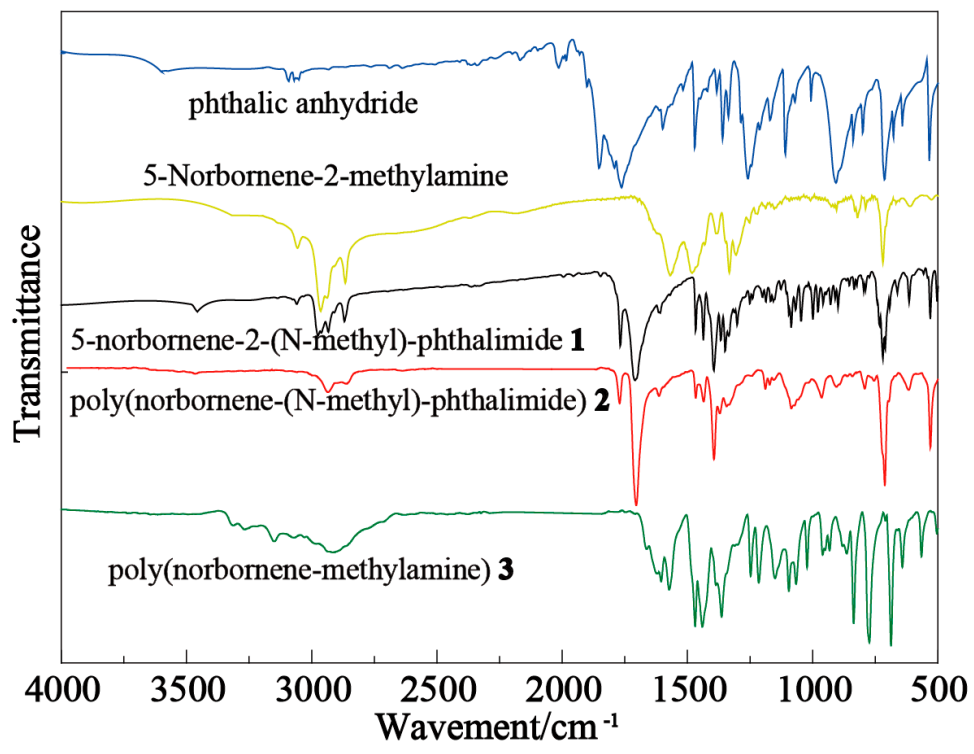

Figure 1. FTIR spectra of raw materials and synthesized products.

Poly(norbornene-(N-methyl)-phthalimide) (Product 2) exhibited a similar FTIR spectrum to that of product 1, except that the stretching vibration peak of $=\mathrm{CH}$ at $3060 \mathrm{~cm}^{-1}$ disappeared due to the ring-opening reaction.

As product 2 was converted to poly(norbornene-methylamine) (Product 3), the peak at $1716 \mathrm{~cm}^{-1}$ that was attributed to the $\mathrm{C}=\mathrm{O}$ group of phthalic anhydride disappeared, and new bands appeared at $3324 \mathrm{~cm}^{-1}, 3276 \mathrm{~cm}^{-1}, 1608 \mathrm{~cm}^{-1}, 1573 \mathrm{~cm}^{-1}$ and $762 \mathrm{~cm}^{-1}$. The bands at $3324 \mathrm{~cm}^{-1}$ and $3276 \mathrm{~cm}^{-1}$ can be assigned to the symmetric and antisymmetric stretching vibrations of $-\mathrm{NH}_{2}$ groups, respectively. The bands at $1608 \mathrm{~cm}^{-1}$ and $1573 \mathrm{~cm}^{-1}$ were due to the in-plane bending vibrations of $\mathrm{N}-\mathrm{H}$ group and that at $762 \mathrm{~cm}^{-1}$ was ascribed to the out-plane wagging vibrations of $\mathrm{N}-\mathrm{H}$ group. These results indicate that target compounds were successfully synthesized and exhibited the expected structures.

\section{2. ${ }^{1} H-N M R$ Characterization}

The ${ }^{1} \mathrm{H}-\mathrm{NMR}$ spectra of the products in each step are shown in Figure 2. The chemical shift at $7.9 \mathrm{ppm}$ of product 1 was ascribed to the $14 \mathrm{H}, 15 \mathrm{H}, 16 \mathrm{H}$ and $17 \mathrm{H}$ on the phenyl ring and the peak at 6.1-6.3 ppm was caused by the $5 \mathrm{H}$ and $6 \mathrm{H}$ on the NBE ring. The peaks at 3.5-3.6 ppm and 3.2-3.3 ppm were due to the $8 \mathrm{H}$ on -( $\mathrm{N}$-methyl)-phthalimide, and the peak at $2.7-2.9 \mathrm{ppm}$ was assigned to the $7 \mathrm{H}$ on the NBE ring bridge. The peaks at 2.4-2.5 ppm and 1.7-1.9 ppm were attributed to the $1 \mathrm{H}$ and $4 \mathrm{H}$ on the NBE ring, respectively. The $3 \mathrm{H}$ and $2 \mathrm{H}$ on the NBE ring caused the chemical shifts at 1.2-1.4 ppm and 0.5-0.6 ppm, respectively.

No significant differences between the ${ }^{1} \mathrm{H}-\mathrm{NMR}$ spectra of products 1 and $\mathbf{2}$ were observed, except that the peak at 6.1-6.3 ppm of product 1 shifted to $5.1-5.6 \mathrm{ppm}$ in the spectrum of product 2 . The shift might be attributed to the transformation of $\mathrm{H}$ on the ring double bond into the $\mathrm{H}$ of double bond on the main chain during the ring-opening reaction of the NBE derivative. The chemical shift at $7.5-7.9 \mathrm{ppm}$ of product 2 was ascribed to the $14 \mathrm{H}, 15 \mathrm{H}, 16 \mathrm{H}$ and $17 \mathrm{H}$ on its phenyl ring. The peaks at 3.3-3.7 ppm was due to the $8 \mathrm{H}$ on -(N-methyl)-phthalimide and the peak at 2.4-3.2 ppm could be 
assigned to the $7 \mathrm{H}$ on NBE ring bridge. The peaks at 1.8-2.3 ppm were ascribed to the $1 \mathrm{H}$ on the NBE ring and those at 1.6-1.8 ppm were attributed to the $4 \mathrm{H}$ on the NBE ring and the $\mathrm{H}$ of $\mathrm{D}_{2} \mathrm{O}$ in the $\mathrm{CDCl}_{3}$ solvent. The chemical shifts at 1.1-1.4 ppm and 0.8-0.9 ppm could be assigned to the $3 \mathrm{H}$ and $2 \mathrm{H}$ on the NBE ring.

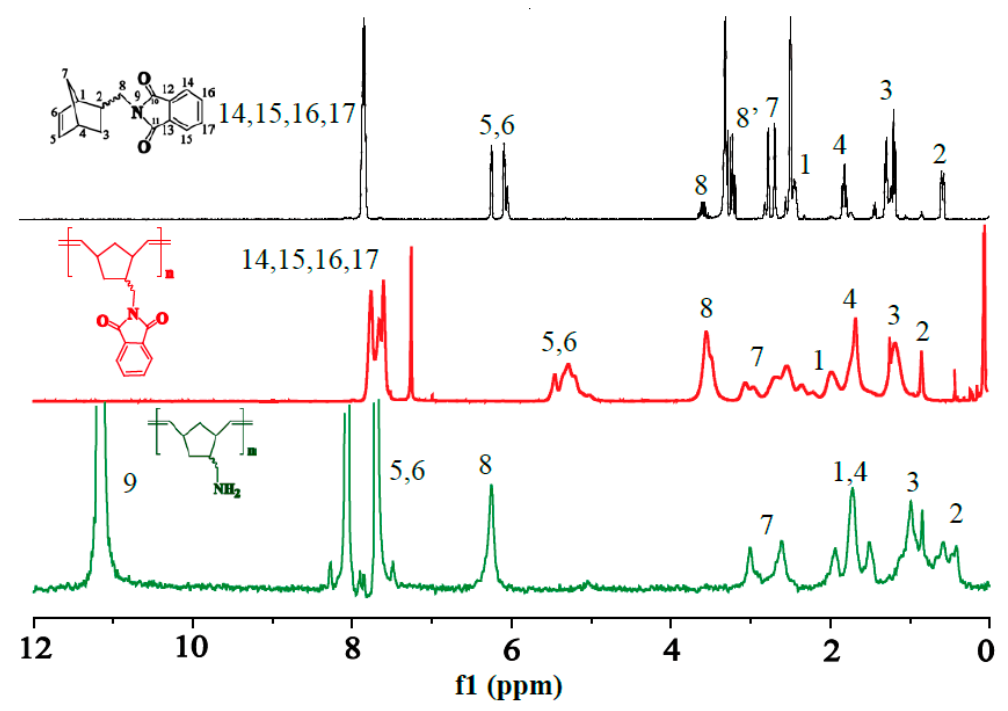

Figure 2. ${ }^{1} \mathrm{H}-\mathrm{NMR}$ spectra of products 1,2 and 3.

Product 3 exhibited a significantly different ${ }^{1} \mathrm{H}-\mathrm{NMR}$ spectrum from product 2 due to the deprotection of phthalic anhydride. The $-\mathrm{NH}_{2}$ group obtained from the removal of phthalic anhydride exhibited an H peak at 11.0-11.1 ppm. The peak at 5.1-5.6 ppm of product 2 shifted to 7.6-8.3 ppm in the spectrum of product 3, possibly because the free $-\mathrm{NH}_{2}$ group is attached to a double bond on the main chain. The peaks at 6.2-6.4 ppm and 2.6-3.1 ppm were assigned to the $8 \mathrm{H}$ on -( $\mathrm{N}$-methyl)-phthalimide and the $7 \mathrm{H}$ on the NBE ring bridge, respectively. The chemical shift at 1.4-2.1 ppm was attributed to the $1 \mathrm{H}$ and $4 \mathrm{H}$ on the NBE ring. The peaks at $0.7-1.2 \mathrm{ppm}$ and $0.4-0.7 \mathrm{ppm}$ were ascribed to the $3 \mathrm{H}$ and $2 \mathrm{H}$ on the NBE ring, respectively.

These ${ }^{1} \mathrm{H}-\mathrm{NMR}$ data indicate that the target products were successfully synthesized.

\subsection{TG Characterization}

The TG and DTG curves of products $\mathbf{2}$ and $\mathbf{3}$ are shown in Figure 3a,b, respectively.

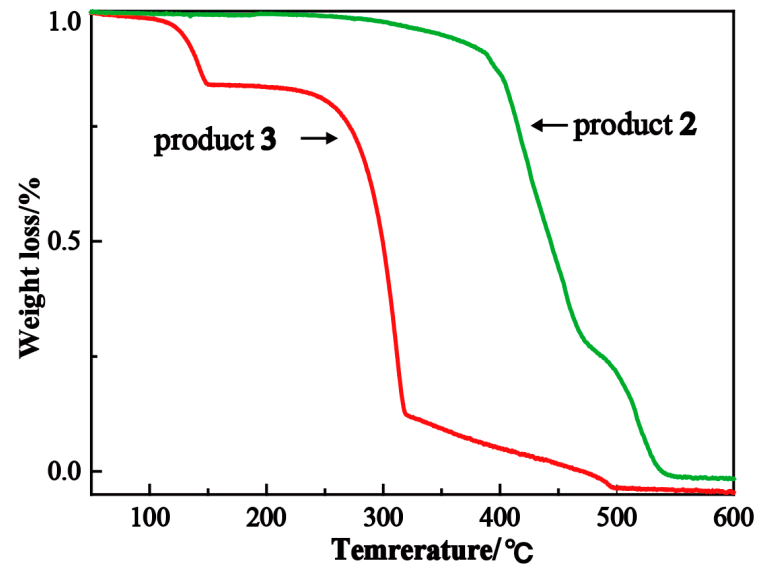

(a)

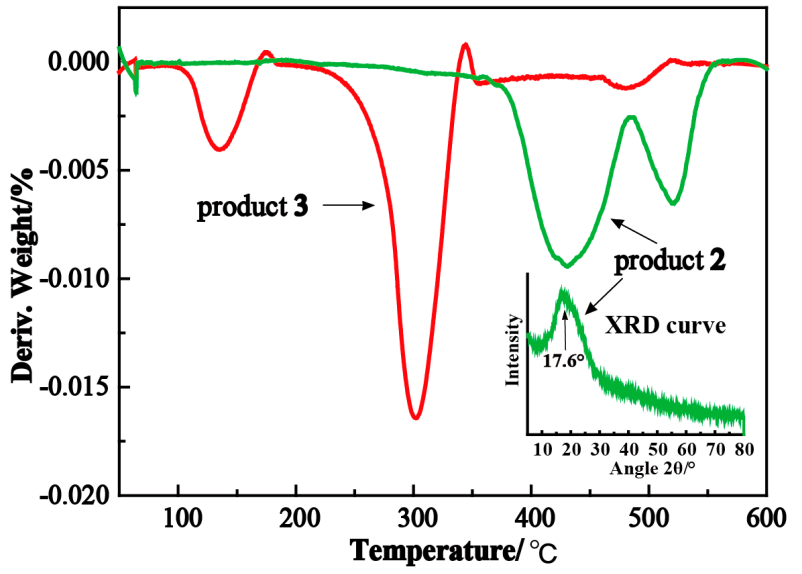

(b)

Figure 3. TG characterization of products 2 and 3. (a) TG curves of products 2 and 3. (b) DTG curves of products 2 and 3 . 
The weight losses of poly(norbornene-( $N$-methyl)-phthalimide) occurred in the temperature ranges of $365-484{ }^{\circ} \mathrm{C}$ and $490-552{ }^{\circ} \mathrm{C}$, respectively. Product 2 exhibited a sharp diffraction peak at $2 \theta=17.6^{\circ}$ (inset in Figure $3 b$ ), indicating its crystalline property. Therefore, the first weight loss might be attributed to the decomposition of the disordered region of poly(norbornene( $N$-methyl)-phthalimide), and the other weight loss at the higher temperature was due to the decomposition of its crystalline region. The first weight loss temperature of $365-484{ }^{\circ} \mathrm{C}$ is higher than that of poly(norbornene-methylamine), possibly because the benzene ring on the side chain of poly(norbornene-(N-methyl)-phthalimide) is more stable than the amino group of poly(norbornene-methylamine).

The first weight loss of poly(norbornene-methylamine) occurred in the temperature range of 97-174 ${ }^{\circ} \mathrm{C}$, due to its highly active amino group that usually reduces the stability of polymer. The active $-\mathrm{NH}_{2}$ group in poly(norbornene-methylamine) might be attached to the double bond in the main chain to form bulky alkyl group by intramolecular cyclization. The interaction between $-\mathrm{NH}_{2}$ and the double bond was reported by Zvonimir et al. [29]. They found that the gas phase basicity of iminocyclopropene could be enhanced by the $\mathrm{NH}_{2}$ groups attached to the $\mathrm{C}=\mathrm{C}$ double bond and subsequent substitution(s) by bulky alkyl group(s). The $\mathrm{NH}_{2}$ groups could release some of the lone pair electron density distribution, enabling a uniform distribution of the positive charge over the whole molecule. The intramolecular cyclization decreased the first weight loss temperature of poly(norbornene-methylamine) from $365-484{ }^{\circ} \mathrm{C}$ to $97-174{ }^{\circ} \mathrm{C}$. Lv reported similar phenomenon in a thermally degradable aliphatic polyester bearing 2-aminoethanethiol -groups (P1) with polyester and amino-BOC (P1-BOC) [30,31]. They found the first weight loss of P1-BOC was initiated at $198.2{ }^{\circ} \mathrm{C}$, due to the fact that the pyrolysis of the $\mathrm{BOC}$ group and $\mathrm{P} 1$ was unstable even at room temperature, because of the nucleophilicity of the pendent amino groups with a five-membered lactam formed by the intramolecular cyclization. Therefore, they concluded that polyesters bearing amino groups that caused larger steric hindrance and weaker nucleophilicity were more thermostable. Similarly, the phthalimide in poly(norbornene-( $N$-methyl)-phthalimide) can reduce the effect of amino groups on double bonds. The main chain of poly(norbornene-methylamine) was decomposed at $224-337^{\circ} \mathrm{C}$, resulting in a second weight loss.

These TG results of product 2 and [3] indicate that poly(norbornene-( $N$-methyl)-phthalimide) was successfully deprotected to afford the target product.

\subsection{Optimization of Synthesise Condition for Product 1}

The amino group of 5-norbornene-2-methylamine can be oxidized by other functional groups during the late reaction stage due to its strong reactivity, which may affect the activity of Grubbs catalyst. Therefore, it is necessary to protect amino groups before the ROMP reaction. To determine the optimal condition for the protection of amino groups, the yields of product $\mathbf{1}$ at different reaction times and temperatures were investigated.

Figure 4 a shows the variation in the yield of product 1 with reaction temperature at the reaction time of $20 \mathrm{~min}$. The yield increased with the increase of reaction temperature, reached the maximum at $130{ }^{\circ} \mathrm{C}$, and decreased as the reaction temperature further increased. This can be explained by the fact that the phthalic anhydride was melted at $130{ }^{\circ} \mathrm{C}$, and thus completely reacted with 5-norbornene -2-methylamine, resulting in the highest yield. 5-norbornene-2-methylamine was evaporated at higher temperatures, which thus reduced the yield.

Figure $4 \mathrm{~b}$ shows the yield changes of product 1 with reaction time at $130{ }^{\circ} \mathrm{C}$. The yield increased with the prolongation of reaction time, reached the maximum at a reaction time of $20 \mathrm{~min}$, and subsequently decreased, with the product becoming a brownish red due to the side reaction as the reaction time further prolonged. 


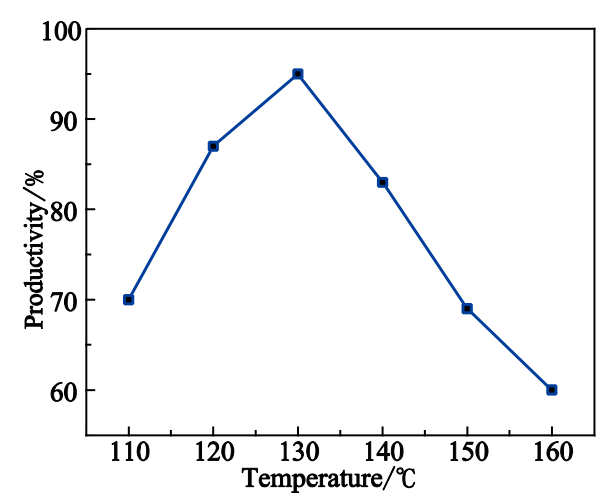

(a)

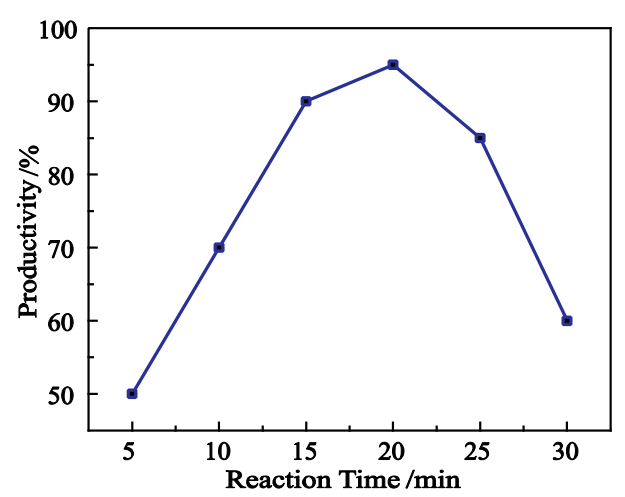

(b)

Figure 4. Yields of product 1 under different reaction conditions. (a) Effects of reaction temperature on the yield of product 1. (b) Effects of reaction time on the yield of product 1 at $130{ }^{\circ} \mathrm{C}$.

In summary, the synthesis condition of product 1 was optimized as: a reaction time of $20 \mathrm{~min}$ and a reaction temperature of $130{ }^{\circ} \mathrm{C}$. The yield of product 1 reached $94.5 \%$ under the optimal synthesis conditions.

\subsection{Molecular Weight and Polydispersity Index}

Figure 5 shows the effects of the molar ratio of monomer ([M]/[I]) on the molecular weight $(\overline{M n})$ and polydispersity index (PDI) of poly(norbornene-( $N$-methyl)-phthalimide) deduced from the GPC results. The $\overline{M n}$ increased linearly with $[\mathrm{M}] /[\mathrm{I}]$ and exhibited a narrow PDI between 1.18 and 1.25. Therefore, the $\overline{M n}$ of poly(norbornene-(N-methyl)-phthalimide) can be tuned by adjusting the $[\mathrm{M}] /[\mathrm{I}]$ ratio.

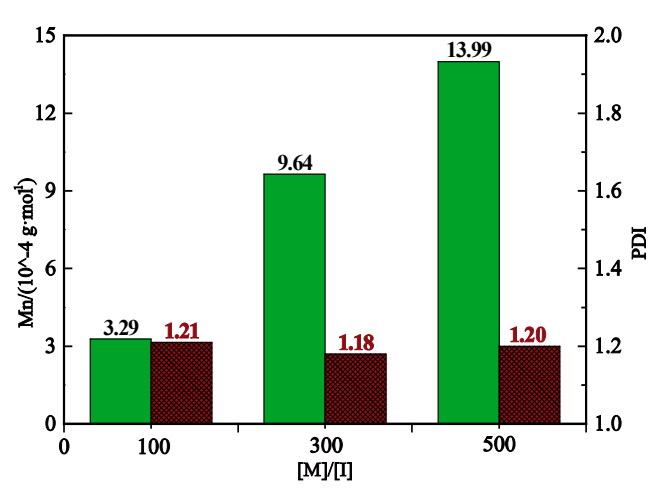

Figure 5. $\overline{M n}$ and PDI of poly(norbornene-(N-methyl)-phthalimide) prepared by a $2 \mathrm{~h}$ ROMP at room temperature with different $[\mathrm{M}] /[\mathrm{I}]$ ratios.

\section{Materials and Methods}

\subsection{Materials}

5-norbornene-2-methylamine ( $\geq 98 \%$ ) was purchased from TCI Development Co., Ltd. (Shanghai, China). Di-tert-butyl dicarbonate and 2,6-di-tert-butyl paracresol were purchased from Sinopharm Chemical Reagent Co., Ltd. (Beijing, China). Phthalic anhydride was provided by Tianjin Xingfu Technology Development Co., Ltd. (Tianjing, China). Ethyl vinyl ether and the 2nd generation Hoveyda-Grubbs catalyst ( $\geq 97 \%$ ) were purchased from Aladdin Industrial Co. (Shanghai, China). Hydrazine hydrate (80\%) was purchased from Beijing Tongguang Fine Chemicals Company (Beijing, China). $\mathrm{CH}_{2} \mathrm{Cl}_{2}$ was dried with $\mathrm{CaH}_{2}$ and freshly distilled prior to use. 5-norbornene-2-methylamine was of gas chromatography grade and spectroscopy grade. Other reagents were of chemical grade. 


\subsection{Synthesis of 5-Norbornene-2-(N-methyl)-phthalimide (Product 1)}

5-norbornene-2-methylamine $(0.246 \mathrm{~g})$ was added to $0.291 \mathrm{~g}$ phthalic anhydride and stirred under nitrogen at $130{ }^{\circ} \mathrm{C}$ for $20 \mathrm{~min}$. The mixture was then added to $15 \mathrm{~mL} n$-hexane, heated to dissolve, cool-crystallized, and dried to afford product 1 .

\subsection{Synthesis of Poly(norbornene-(N-methyl)-phthalimide) (Product 2)}

One milligram Grubbs II catalyst was dissolved in $1 \mathrm{~mL} \mathrm{CH}_{2} \mathrm{Cl}_{2}$, vacuum aerated with nitrogen for 3 times, and stirred under nitrogen for $15 \mathrm{~min}$. The catalyst solution was added to $3 \mathrm{~mL}$ product 1 $(0.1 \mathrm{~g})$ solution and stirred under nitrogen at room temperature for $2 \mathrm{~h}$. To terminate the polymerization reaction, ethyl vinyl ether was added to the reaction solution and stirred for an additional $20 \mathrm{~min}$. The final solution was poured into $400 \mathrm{~mL}$ of methanol to precipitate the polymer that was then dried to afford product 2 .

\subsection{Synthesis of Poly(norbornene-methylamine) (Product 3)}

Product $2(0.2 \mathrm{~g})$ was dissolved in $10 \mathrm{~mL}$ ethanol and refluxed with $2 \mathrm{~mL}$ of hydrazine hydrate and a certain amount of 2, 6-Di-tert-butyl-4-methylphenol under nitrogen at $100{ }^{\circ} \mathrm{C}$ for $8 \mathrm{~h}$. The reaction solution was cooled to room temperature and precipitated with $\mathrm{CH}_{2} \mathrm{Cl}_{2}$. The precipitate was dried to afford product 3 .

\subsection{Characterization}

IR spectra were recorded on a Nicolet8700 FT-IR spectrometer that manufactured by Thermo Nicolet Co., (Madison, WI, USA) in the range of $4000-500 \mathrm{~cm}^{-1}$ at a resolution of $4 \mathrm{~cm}^{-1}$ using $\mathrm{KBr}$ pellets.

${ }^{1} \mathrm{H}-\mathrm{NMR}$ spectra were measured with a Bruker $500 \mathrm{MHz}$ NMR spectrometer using TMS in DMSO, $\mathrm{CDCl}_{3}$ and $\mathrm{CF}_{3} \mathrm{COOD}$ as the internal standards for 5-norbornene-2-( $\mathrm{N}$-methyl)-phthalimide, poly(norbornene-( $\mathrm{N}$-methyl)-phthalimide) and poly(norbornene-methylamine), respectively.

Gel permeation chromatography (GPC) was conducted on a system containing a GPC detector (Waters Breeze HPLC, Waters Company, Framingham, MA, USA) and PSS Waters HR-3, HR-4 and HR- 6 columns at $35^{\circ} \mathrm{C}$. Tetrahydrofuran (THF) was used as the mobile phase.

Thermogravimetric analysis (TG) was performed on a DTG-60 TGA/DTA Analyzer (Shimadzu, Japan). The sample was heated from $30^{\circ} \mathrm{C}$ to $600{ }^{\circ} \mathrm{C}$ at $10^{\circ} \mathrm{C} / \mathrm{min}$ under $50 \mathrm{~mL} / \mathrm{min}$ nitrogen flow.

\section{Conclusions}

In the current study, poly(norbornene-methylamine) was prepared by ROMP for the first time. 5-norbornene-2-( $N$-methyl)-phthalimide was first prepared by the reaction between 5-norbornene-2-methylamine and phthalic anhydride with the highest yield of $94.5 \%$ achieved at $130{ }^{\circ} \mathrm{C}$ for $20 \mathrm{~min}$. The ROMP reaction of 5-norbornene-2-(N-methyl)-phthalimide proceeded in the presence of Hoveyda-Grubbs 2nd catalyst to form poly(norbornene-( $N$-methyl)-phthalimide). The molecular weight $(\overline{M n})$ of poly(norbornene-(N-methyl)-phthalimide) increased linearly with the increase of $[\mathrm{M}] /[\mathrm{I}]$ ratio and exhibited a narrow PDI range of 1.18-1.25. Poly(norbornene-( $N$-methyl)-phthalimide was deprotected to afford the target polymer, poly(norbornene-methylamine). The products of each step were characterized with FTIR, ${ }^{1} \mathrm{H}-\mathrm{NMR}$ and TG. Our study provides a strategy for synthesizing chitosan like polymers bearing free $-\mathrm{NH}_{2}$ groups with controllable structures via ROMP.

Acknowledgments: The authors gratefully acknowledge the financial support of the Combination Project of Guangdong Province and the "Yangfan" Innovative Research Team Project of Guangdong Province.

Author Contributions: Yu Chen, Na Li and Huanhuan Wang conceived and designed the experiments; Huanhuan Wang performed the experiments; Yu Chen, Na Li and Huanhuan Wang analyzed the data; Yu Chen, $\mathrm{Na} \mathrm{Li}$ and Xiaosai Qu wrote the paper.

Conflicts of Interest: The authors declare no conflict of interest. 


\section{References}

1. Yu, X.; Mu, C.; Dai, D. Well-Defined Magnetic Responsive Polymers Containing Ammonium $\mathrm{FeCl}_{4}$ from ROMP. Macromol. Chem. Phys. 2016, 217, 2700-2707. [CrossRef]

2. Nomura, K.; Abdellatif, M.M. Precise synthesis of polymers containing functional end groups by living ring-opening metathesis polymerization (ROMP): Efficient tools for synthesis of block/graft copolymers. Polymer 2010, 51, 1861-1881. [CrossRef]

3. Ferrer, Í.; Rich, J.; Fontrodona, X. Ru(II) complexes containing dmso and pyrazolyl ligands as catalysts for nitrile hydration in environmentally friendly media. Dalton Trans. 2013, 42, 13461-13469. [CrossRef] [PubMed]

4. Schrock, R.R. Synthesis of Stereoregular Polymers through Ring-Opening Metathesis Polymerization. Acc. Chem. Res. 2014, 47, 2457-2466. [CrossRef] [PubMed]

5. Hyvl, J.; Autenrieth, B.; Schrock, R.R. Proof of Tacticity of Stereoregular ROMP Polymers through Post Polymerization Modification. Macromolecules 2015, 48, 3148-3152. [CrossRef]

6. Autenrieth, B.; Jeong, H.; Forrest, W.P. Stereospecific Ring-Opening Metathesis Polymerization (ROMP) ofendo-Dicyclopentadiene by Molybdenum and Tungsten Catalysts. Macromolecules 2015, 48, 2480-2492. [CrossRef]

7. Martinez, H.; Hillmyer, M.A. Ring-Opening metathesis polymerization of 8-membered cyclic olefins. Polym. Chem. 2014, 5, 3507-3532. [CrossRef]

8. Parker, K.A.; Sampson, N.S. Precision Synthesis of Alternating Copolymers via Ring-Opening Polymerization of 1-Substituted Cyclobutenes. Acc. Chem. Res. 2016, 49, 408-417. [CrossRef] [PubMed]

9. Gu, H.; Ciganda, R.; Castel, P. Living ROMP Syntheses and Redox Properties of Triblock Metallocopolymer Redox Cascades. Macromolecules 2016, 49, 4763-4773. [CrossRef]

10. Wang, Y.; Rapakousiou, A.; Astruc, D. ROMP Synthesis of Cobalticenium-Enamine Polyelectrolytes. Macromolecules 2014, 47, 3767-3774. [CrossRef]

11. Martinez, H.; Hillmyer, M.A. Carboxy-Telechelic Polyolefins in Cross-Linked Elastomers. Macromolecules 2014, 47, 479-485. [CrossRef]

12. Annunziata, L.; Fouquay, S.; Michaud, G. Mono- and di-cyclocarbonate telechelic polyolefins synthesized from ROMP using glycerol carbonate derivatives as chain-transfer agents. Polym. Chem. 2013, 4, 1313-1316. [CrossRef]

13. Vanbiervliet, E.; Fouquay, S.; Jean-Francois, C. From Epoxide to Cyclodithiocarbonate Telechelic Polycyclooctene through Chain-Transfer Ring-Opening Metathesis Polymerization (ROMP): Precursors to Non-Isocyanate Polyurethanes (NIPUs). Macromolecules 2017, 50, 69-82. [CrossRef]

14. Bingöl, B.; Kroeger, A.; Jannasch, P. Well-defined phosphonated homo- and copolymers via direct ring opening metathesis polymerization. Polymer 2013, 54, 6676-6688. [CrossRef]

15. Ferraz, C.P.; Fonseca, L.R.; Tomazetti, V. Copolymers from norbornene and norbornadiene with organized morphologies and high Tg values obtained via ROMP with a highly reactive $\left[\mathrm{RuCl} 3\left(\mathrm{PCy}_{3}\right)_{2}\right]$ complex. New J. Chem. 2016, 40, 9424-9431. [CrossRef]

16. Suga, T.; Sakata, M.; Aoki, K. Synthesis of Pendant Radical- and Ion-Containing Block Copolymers via Ring-Opening Metathesis Polymerization for Organic Resistive Memory. ACS Macro Lett. 2014, 3, $703-707$. [CrossRef]

17. Leroux, F.; Montembault, V.; Piogé, S. High Molar Mass Poly(1,4-butadiene)-graft-poly(e-caprolactone) Copolymers by ROMP: Synthesis via the Grafting-From Route and Self-Assembling Properties. Macromolecules 2016, 49, 4739-4745. [CrossRef]

18. Xu, G.; Wang, D.; Buchmeiser, M.R. Functional Polyolefins: Poly(ethylene)-graft-Poly(tert-butyl acrylate) via Atom Transfer Radical Polymerization From a Polybrominated Alkane. Macromol. Rapid Commun. 2012, 33, 75-79. [CrossRef] [PubMed]

19. Eissa, A.M.; Khosravi, E. Comb-Like Graft Copolymers of Poly(oxa)norbornene: Efficient Synthesis Using a Combination of ROMP and Click Chemistry. Macromol. Chem. Phys. 2015, 216, 964-976. [CrossRef]

20. Zhang, Z.Y.; Liao, P.L.; Shen, Z.H. Precise size control of sub-10 nm structures of cholesteryl-containing mesogen-jacketed liquid crystalline polymers. Polymer 2016. [CrossRef]

21. Wang, L.Y.; Li, Y.F.; Zhu, F.M. Homo- and copolymerizaton of norbornene and norbornene derivative with $\mathrm{Ni}$ - and Pd-based $\beta$-ketoiminato complexes and MAO. Eur. Polym. J. 2006, 42, 322-327. [CrossRef] 
22. Chung, T.C. Synthesis of functional polymers via borane monomers and metathesis catalysts. J. Mol. Catal. 1992, 76, 15-31. [CrossRef]

23. Santiago, A.A.; Cruz-Morales, J.A.; Vargas, J.; Tlenkopatchev, M.A.; Gavino, R.; Malkanduev, Y.A.; Sivov, N.A. Synthesis of New Polymer Ionomers via Ring-Opening Metathesis Polymerization. Open J. Org. Polym. Mater. 2014, 4, 84-91. [CrossRef]

24. Pawar, G.M.; Weckesser, J.; Blechert, S.; Buchmeiser, M.R. Ring opening metathesis polymerization-derived block copolymers bearing chelating ligands: Synthesis, metal immobilization and use in hydroformylation under micellar conditions. Beilstein J. Org. Chem. 2010, 6, 28. [CrossRef]

25. Ren, L.; Zhang, J.; Bai, X. Preparation of cationic cobaltoceniumpolymers and block copolymers by "living" ring-opening metathesispolymerization. Chem. Sci. 2012, 3, 580-583. [CrossRef]

26. Ashok Kothapalli, V.; Shetty, M.; de Los Santos, C. Thio-bromo "Click," post-polymerization strategy for functionalizing ring opening metathesis polymerization (ROMP)-derived materials. J. Polym. Sci. Part A Polym. Chem. 2016, 54, 179-185. [CrossRef]

27. Alfred, S.F.; Lienkamp, K.; Madkour, A.E. Water-soluble ROMP polymers from amine-functionalized norbornenes. J. Polym. Sci. Part A Polym. Chem. 2008, 46, 6672-6676. [CrossRef]

28. Li, P.; Zhao, J.; Chen, Y. Preparation and characterization of chitosan physical hydrogels with enhanced mechanical and antibacterial properties. Carbohydr. Polym. 2017, 157, 1383-1392. [CrossRef] [PubMed]

29. Zvonimir, B.M.; Borislav, K. Spatial and electronic structure of highly basic organic molecules: Cyclopropeneimines and some related systems. J. Phys. Chem. A 1999, 103, 6678-6684.

30. Lv, A.; Cui, Y.; Du, F.-S.; Li, Z.-C. Thermally Degradable Polyesters with Tunable Degradation Temperatures via Postpolymerization Modification and Intramolecular Cyclization. Macromolecules 2016, 49, 8449-8458. [CrossRef]

31. Lv, A.; Li, Z.-L.; Du, F.-S.; Li, Z.C. Synthesis, Functionalization, and Controlled Degradation of High Molecular Weight Polyester from Itaconic Acid via ADMET Polymerization. Macromolecules 2014, 47, 7707-7716. [CrossRef] 